\title{
The aeolian sedimentary system along the transition between the Qilian Shan and northern Chinese drylands during the late Quaternary
}

\author{
Veit Nottebaum
}

Email: veit.nottebaum@geo.rwth-aachen.de

University: Department of Geography, RWTH Aachen University

Supervisors: Frank Lehmkuhl, Bernhard Diekmann

Dissertation Online: https://publications.rwth-aachen.de/record/567364/files/567364.pdf

Central Asia hosts different large-scale wind systems (i.e., Westerlies, the Asian monsoon system) which interact along the transition between the Tibetan Plateau, the Chinese Loess Plateau, and northern Chinese deserts. This study focuses on the distribution of (mainly) aeolian sediments, involved geomorphological processes, and palaeoenvironmental implications in this transition zone between high mountains and deserts during the late Quaternary. A sample set of almost 800 sedimentological samples and 58 Optically Stimulated Luminescence (OSL) samples was obtained from the Qilian Shan mountain range and its northern foreland. Different geomorphological settings were sampled to assess spatial and temporal distribution patterns and evaluate geomorphological influences and palaeoenvironmental changes among sediment properties.

Between the Qilian Shan ( $<5700 \mathrm{~m}$ asl) and its foreland basins (Hexi Corridor; <2000 m asl), a sediment classification based on grain size analysis yields six major sediment types which are distributed in three major sedimentological landscape units along an altitudinal cross section: I) Periglacial debris and glaciofluvial sediments above $3800 \mathrm{~m}$ asl. II) Primary loess is dominantly preserved between 3800 and $2000 \mathrm{~m}$ asl. III) Below $2000 \mathrm{~m}$ asl aeolian sands alternate with lacustrine deposits and gravel gobi surfaces (Nottebaum et al., 2014). Focusing on loess grain size, a significant fining trend is evident with increasing altitude. An increased contribution from far distant dust sources caused by stronger Westerly influence in altitudes $>3000 \mathrm{~m}$ asl leads to a larger fine silt proportion. Additionally, steep mountain topography restricts the fluvial sand supply compared to flat foreland topography where rivers tend to aggradation (NotTeBAum et al. 2014).

Loess deposition started during the PleistoceneHolocene transition at around 12 ka (ZHANG et al. 2015). Statistical decomposition of loess grain size distributions resulted in three contributing end-members, which were used to reconstruct the relative contribution from different transport processes: I) short-distance transport from mainly fluvial storages, II) dust storm contribution and III) long distance transport in high suspension clouds (NoTTEBAUM et al. 2015a). As the relative proportion of each of these transport processes is depending on the surrounding geomorphological and environmental setting, a reconstruction of landscape conditions can be approached. Although bulk grain size variations were only slight, a consistent reconstruction of environmental conditions, with respect to spatial geomorphologic variability, is presented. During the onset of loess deposition the foreland areas exhibited vast alluvial fan surfaces providing large sand amounts for deflation, which is represented in the local transport component of loess deposits. This observation reflects a rather instable landscape state, still influenced by the glacial time's sediment supply. The mid-Holocene loess exhibits the highest proportion of fine materials, indicative for fartravelled dust (Noттеваum et al. 2015a). This implies that surrounding surfaces were relatively stable and sand availability was low as a result of the yet developed loess cover on alluvial fan surfaces and dense vegetation covers. As a prerequisite for dust-trapping, a rather dense vegetation cover existed which implies moist climatic conditions. The late Holocene records exhibit a declining trend of longdistance contribution and an enhanced dust storm input. This reflects higher availability of dust particles in sourceand bypassing areas (e.g., lacustrine and fluvial deposits of northerly deserts and lower Hexi Corridor).

Aeolian sand accumulation frequently occurred during the Holocene in the central Hexi Corridor, while deflation dominated in its western part. The comparison of OSL ages shows high accumulation in the western part during the Pleistocene-Holocene transition. In contrast, the central 


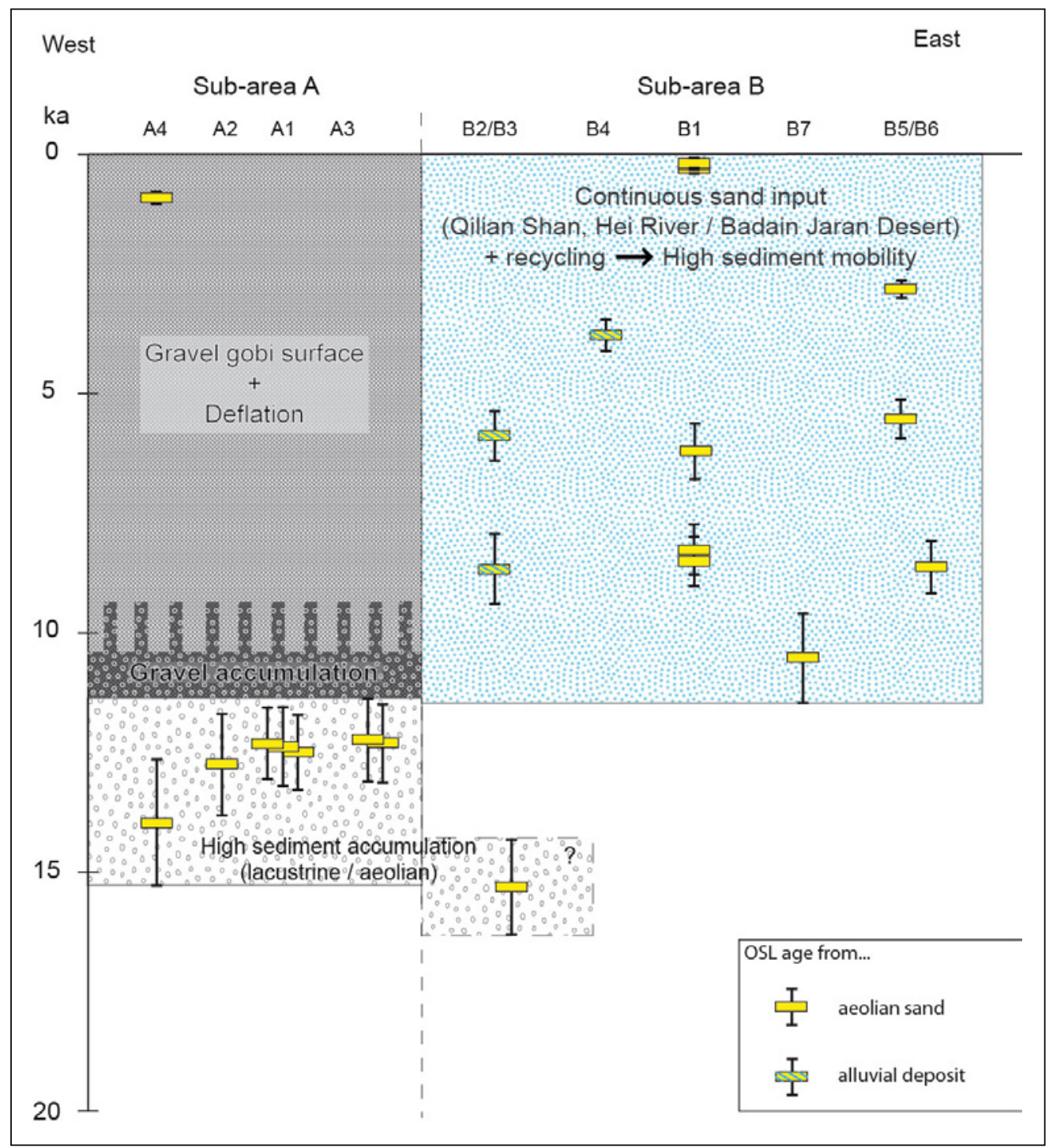

Fig. 1: Interpretation of geomorphologic, sedimentologic, and chronologic evidence for landscape evolution in western and central Hexi Corridor (NotTeBAum et al., 2015b).

Hexi Corridor exhibits aeolian sand ages throughout the entire Holocene (Fig. 1). The difference in this sedimentologic behaviour is attributed to a shortage in sediment supply in western parts, while the central Hexi Corridor receives higher precipitation and is crossed by several perennial streams providing material from fluvial storages for deflation (NotTebAum et al. 2015b).

A comparison of loess and aeolian sand deposits show considerable differences in their reaction to environmental change, also because the hosting geomorphological settings differ. This study presents an approach of studying the comprehensive aeolian sedimentary system. As such, loess deposits are preserved on stable terrace surfaces and in upper regions during periods of relatively moist climatic conditions causing river incision and fluvial reworking of storages. In contrast, aeolian sands located in lowland regions are fed and reworked by enhanced fluvial activity.

Sediment supply is identified as the limiting factor for the formation of aeolian sand deposits in the Hexi Corridor. The same applies to the sand fraction in loess deposits. For loess accumulation, however, a stable geomorphologic surface and a dust-trapping vegetation cover are required. The investigation of adjacent geomorphological units exhibiting loess and aeolian sand is promising, because both archives reflect different behaviours in a geomorphologic and temporal context. A diverse set of surface samples allows a better evaluation of medium-scale geomorphologic influences on transport processes, which is also useful for the interpretation of long vertical sections. Comparing sedimentological and geochronological observations in aeolian sediments is found promising for the reconstruction of I) sedimentary processes as part of a greater sediment cascade and II) for the reconstruction of palaeoenvironmental conditions.

Nottebaum, V., Lehmkuhl, F., Stauch, G., Hartmann, K., Wünnemann B., Schimpf, S. \& Lu, H. (2014): Regional grain size variations in aeolian sediments along the transition between Tibetan highlands and north-western Chinese deserts - the influence of geomorphological settings on aeolian transport pathways. - Earth Surface Processes and Landforms 39, 1960-1978.

Nottebaum, V., Stauch, G., Hartmann, K., Zhang, J. \& Lehmkuhl, F. (2015a): Unmixed loess grain size populations along the northern Qilian Shan (China): relationships between geomorphologic, sedimentologic and climatic controls. - Quaternary International 372, 151-166.

Nottebaum, V., Lehmkuhl, F., Stauch, G., Lu, H. \& Shuangwen, Y. (2015b): Late Quaternary aeolian sand deposition sustained by fluvial reworking and sediment supply in the Hexi Corridor - An example from northern Chinese drylands. - Geomorphology 250, 113-127.

Zhang, J., Nottebaum, V., Tsukamoto, S., Lehmkuhl, F. \& Frechen, M. (2015): Late Pleistocene and Holocene loess sedimentation in central and western Qilian Shan (China) revealed by OSL dating. - Quaternary International 372, 120-129. 